\title{
Neuroactive steroids, their metabolites, and neuroinflammation
}

\author{
Silvia Giatti ${ }^{1,2 \star}$, Mariaserena Boraso ${ }^{1 *}$, Roberto Cosimo Melcangi ${ }^{1,2}$ and Barbara Viviani ${ }^{1}$ \\ ${ }^{1}$ Dipartimento di Scienze Farmacologiche e Biomolecolari and ${ }^{2}$ Center of Excellence on Neurodegenerative Diseases, Università degli Studi di Milano, Milano, Italy \\ (Correspondence should be addressed to R C Melcangi who is now at Dipartimento di Scienze Farmacologiche e Biomolecolari, Center of Excellence on Neurodegenerative Diseases, \\ Università degli Studi di Milano, Via Balzaretti 9, 20133 Milano, Italy; Email: roberto.melcangi@unimi.it) \\ *(S Giatti and M Boraso contributed equally to this work)
}

\begin{abstract}
Neuroinflammation represents a common feature of many neurodegenerative diseases implicated both in their onset and progression. Neuroactive steroids act as physiological regulators and protective agents in the nervous system. Therefore, the attention of biomedical research has been recently addressed in evaluating whether neuroactive steroids, such as progestagens, androgens, and estrogens may also affect neuroinflammatory pathways. Observations so far obtained suggest a general anti-inflammatory effect with a beneficial relapse on several neurodegenerative experimental models, thus confirming the potentiality of a neuroprotective strategy based on neuroactive steroids. In this scenario, neuroactive steroid metabolism and the sophisticated machinery involved in their signaling are becoming especially attractive. In particular, because metabolism of neuroactive steroids as well as expression of their receptors is affected during the course of neurodegenerative events, a crucial role of progesterone and testosterone metabolites in modulating neuroinflammation and neurodegeneration may be proposed. In the present review, we will address this issue, providing evidence supporting the hypothesis that the efficacy of neuroactive steroids could be improved through the use of their metabolites.
\end{abstract}

Journal of Molecular Endocrinology (2012) 49, R125-R134

\section{Introduction}

Neuroactive steroids act as important physiological regulators of CNS functions (Melcangi et al. 2008, 2011, Panzica et al. 2012). Moreover, as demonstrated in experimental models of several neurodegenerative disorders, the administration of neuroactive steroids is able to favor several protective/reparative processes like inhibition of neuronal death, promotion of neurogenesis, and myelination, as well as reduction of neuroinflammation (Brinton \& Wang 2006, Garcia-Segura \& Balthazart 2009, Melcangi \& Garcia-Segura 2010, Melcangi et al. 2011, Kipp et al. 2012, Panzica et al. 2012, Schumacher et al. 2012). Intriguing is the modulation of this last process. Neuroinflammation is shared by a number of pathologies, ranging from neurodegenerative to psychiatric diseases (Glass et al. 2010, Tansey 2010, Tansey \& Goldberg 2010, Wee Yong 2010, Wuwongse et al. 2010, Meyer et al. 2011) and represents an early response to any perturbation of the CNS physiology leading to dysfunction and degeneration when deregulated
(Block et al. 2007). Thus, the possibility to modulate this phenomenon becomes valuable in terms of preventing disease progression.

An emerging issue in the field of neuroactive steroids is the role of progesterone (PROG) and testosterone metabolites. In particular, the observation that metabolites are i) more active than the precursor molecule (Melcangi et al. 2008), ii) appear to be necessary for some of the effects exerted by PROG or testosterone (Ghoumari et al. 2003, Giachino et al. 2003, 2004, Ciriza et al. 2004, 2006, Djebaili et al. 2004, He et al. 2004, Pesaresi et al. 2010a, Sun et al. 2012), and iii) their synthesis is impaired in CNS diseases (Labombarda et al. 2006, Meffre et al. 2007, Caruso et al. 2008, 2010, Giatti et al. 2010, Naylor et al. 2010, Pesaresi et al. 2010b, Melcangi et al. 2012) suggest that these molecules might share a higher therapeutic impact than classical hormones like PROG and testosterone.

The present review will recapitulate what is known about the anti-inflammatory properties of neuroactive steroids, with a particular focus on PROG and testosterone metabolites.

DOI: 10.1530/JME-12-0127 Online version via http://www.endocrinology-journals.org 


\section{Neuroactive steroids: state of the art}

The nervous system is a well-known target for the endocrine effects of hormonal steroids coming from peripheral steroidogenic glands. However, the nervous system is also controlled in a paracrine and autocrine manner by steroids directly synthesized by neurons and glial cells, named neurosteroids (Baulieu 1998). More recently, this concept was expanded into the neuroactive steroid family, including hormonal steroids, neurosteroids, and synthetic steroids that are able to regulate several neuronal functions (Melcangi et al. 2008).

Synthesis and metabolism of neuroactive steroids occur in neurons and glial cells (Garcia-Segura \& Melcangi 2006, Melcangi et al. 2008, Panzica \& Melcangi 2008, Pelletier 2010). Steroidogenesis is a process highly compartmentalized in a sequence of reactions, which implies as a first step the translocation of cholesterol from the cytoplasm to the mitochondrial membrane (Fig. 1). This is a limiting step hormonally controlled and mediated by the StAR (Lavaque et al. $2006 a, b)$ and $18 \mathrm{kDa}$ translocator protein (Papadopoulos et al. 2006). In the mitochondria, the enzyme $\mathrm{P} 450$ side chain cleavage (P450scc) converts cholesterol into pregnenolone (PREG), which is further transformed into PROG or DHEA in the endoplasmic reticulum (Melcangi et al. 2008). Notably, these molecules exert effects on the CNS per se, but may undergo metabolic transformations leading to the formation of neuroactive metabolites. Due to their lipophilic structure, neuroactive steroids move from one cell to another. This greatly impacts their metabolism that will be ruled by the enzymatic repertoire expressed in different cell types. For example, DHEA can be converted into androstenediol, and subsequently into testosterone, or into androstenedione in all the cells of the CNS (Melcangi et al. 2008). In neurons, androstenedione, as well as testosterone, may be converted by the enzyme P450 aromatase (ARO) to estrone and $17 \beta$-estradiol $\left(17 \beta-\mathrm{E}_{2}\right)$ respectively. This occurs also in astrocytes, which display ARO, but not in microglia (Garcia-Segura et al. 2003). In neurons, as well as in astrocytes, PROG and testosterone may be metabolized by the enzymatic complex formed by $5 \alpha$-reductase $(5 \alpha-\mathrm{R})$ and $3 \alpha-$ hydroxysteroid dehydrogenase ( $3 \alpha$-HSD) into dihydroprogesterone (DHP) and tetrahydroprogesterone (THP), also known as allopregnanolone, or dihydrotestosterone (DHT) and $5 \alpha$-androstane- $3 \alpha, 17 \beta$-diol (3 $\alpha$-Diol) respectively (Melcangi et al. 2008). Although these pathways are shared by microglia, this cell type is not able to produce PREG or PROG. Moreover, expressing $17 \beta$-HSD, they synthesize androstenediol from DHEA (Jellinck et al. 2007) and testosterone from

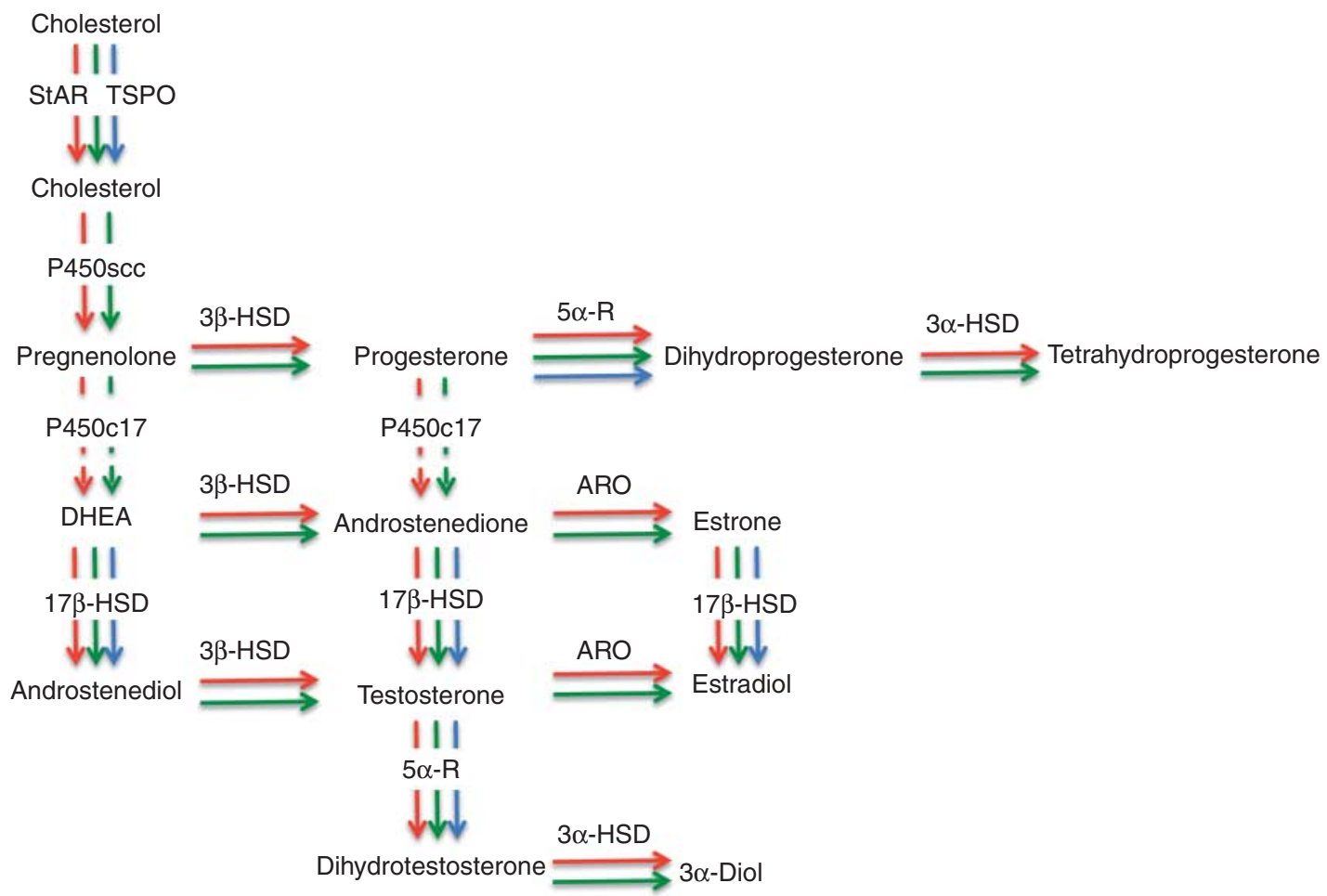

Figure 1 Schematic representation of neurosteroidogenesis. Arrows represent cellular localization in neurons (red), astrocytes (green), and microglia (blue). 
androstenedione (Jellinck et al. 2006, 2007). Finally, since ARO is not expressed, microglial cells produce estradiol only from estrone and not from testosterone (Gottfried-Blackmore et al. 2008).

The metabolism of PROG and testosterone has a deep impact on the mechanism of action of these neuroactive steroids. Indeed, while DHP, like PROG, is able to interact with the classical steroid receptor, the PROG receptor (PR; Melcangi et al. 2008), THP is a potent ligand of a non-classical steroid receptor, such as the GABA-A receptor (Lambert et al. 2003, Belelli \& Lambert 2005). Similarly, DHT is able to interact with the androgen receptor (AR) while $3 \alpha$-diol is a ligand of the GABA-A receptor (Melcangi et al. 2008). Thus, metabolic conversion of PROG and testosterone into their derivatives might differently and specifically modulate the mechanism of action of the respective precursor molecules by recruiting CNS-specific pathways.

Both neurons and glial cells express classical steroid receptors (Melcangi et al. 2001, 2008, Brinton et al. 2008). However, not all glial cell types express the same repertoire of steroid receptors and their expression changes in relation to the activation state of cells, to the regional localization and the developmental stage. For instance, estrogen receptor $\alpha(\mathrm{ER} \alpha)$ is expressed in microglial cells, while ER $\beta, A R$, and PR seem not to be under physiological conditions (Sierra et al. 2007, 2008). In male rats, AR-positive astrocytes were observed in the cerebral cortex, but only in postnatal day 10 animals (DonCarlos et al. 2006), while in the adult animals AR-positive astrocytes were observed in the arcuate nucleus and in the hippocampal formation (Tabori et al. 2005, DonCarlos et al. 2006).

Both steroid receptor expression and metabolism are modified by different insults. In rats, for example, brain injury induces the expression of $\mathrm{ER} \alpha$ in vimentin or glial fibrillary acidic protein (GFAP)-positive astrocytes and of AR in Griffonia simplicifolia lectin-1 or MHC-IIpositive microglia, suggesting that the expression of several receptors in different cell types is necessary for the correct modulation of the response to the insults (García-Ovejero et al. 2002).

\section{Neuroinflammation: the main features}

Neuroinflammation is a local CNS inflammatory reaction, which represents the coordinated cellular and molecular response to injurious stimuli, aimed at eliminating or neutralizing them and restoring tissue integrity (Fig. 2). The appropriate regulation of this process facilitates recovery, while uncontrolled neuroinflammation contributes to pathology.

Microglia and astrocytes are the two cell types resident within the CNS and mainly involved in the local organization of the neuroinflammatory response. Microglia are involved in regulatory processes critical for development, maintenance of neuronal environment, repair, and injury. In the normal, healthy brain, these cells are in a so-called 'resting state' characterized by low expression of membrane receptors that serve immunological functions (Hanisch \& Kettenmann 2007). Although 'resting', microglia constantly monitor for changes in the surrounding environment and are ready to get activated to fight off any threats to tissue integrity. When stimulated, microglia acquire an ameboid morphology and present an upregulated catalog of surface molecules (Oehmichen \& Gencic 1975, Cho et al. 2006), such as MHC, chemokine receptors, and CD14 (Rock et al. 2004). This activated state also coincides with the production of soluble mediators both detrimental, such as pro-inflammatory cytokines, reactive oxygen species, and reactive nitrogen species (Sawada et al. 1989, Moss \& Bates 2001, Viviani et al. 2001, Liu et al. 2002, Tansey et al. 2007), and beneficial (i.e. anti-inflammatory cytokines and tropic factors) (Morgan et al. 2004, Liao et al. 2005, Muller et al. 2006; Fig. 2). A balanced production of those factors contributes to restore CNS function.

While microglial cells are generally considered as the main resident immune cells of the brain, it is important to note that astrocytes are immunocompetent cells as well, and they also act as important regulators of CNS inflammation. Astrocytes are the most abundant glial cells and are essential for brain homeostasis and neuronal functions (Benarroch 2005, Farina et al. 2007). Like microglia, astrocytes become activated - a process known 'astrogliosis', which is characterized by altered gene expression, increased expression of marker molecules (i.e. GFAP and vimentin), hypertrophy, and proliferation (Ridet et al. 1997). Activated astrocytes release as well a wide array of immune mediators such as cytokines, chemokines, and growth factors, contributing either to neuroprotective or neurotoxic effects (Farina et al. 2007) raised by microglia (Fig. 2).

The neuroinflammatory response is not only confined to glial cells. Peripheral immune cells also, and no less crucially, participate (Schwartz et al. 2006). In fact, the release of the above mediators by glial cells leads to the recruitment of macrophages, monocytes, and lymphocytes ( $\mathrm{T}$ and $\mathrm{B}$ cells) that participate in sustaining the local response to an acute or chronic CNS insult (Schwartz et al. 2006). This easily occurs through the compromised blood-brain barrier (BBB), a feature accompanying several CNS diseases. T-cell invasion of the CNS determines the organization of an adaptive immune response whose quality will be defined by the characteristics of the invading lymphocytes. In fact, in response to inflammatory events, $\mathrm{CD} 4+\mathrm{T}$ helper $(\mathrm{Th})$ cells can potentially differentiate 


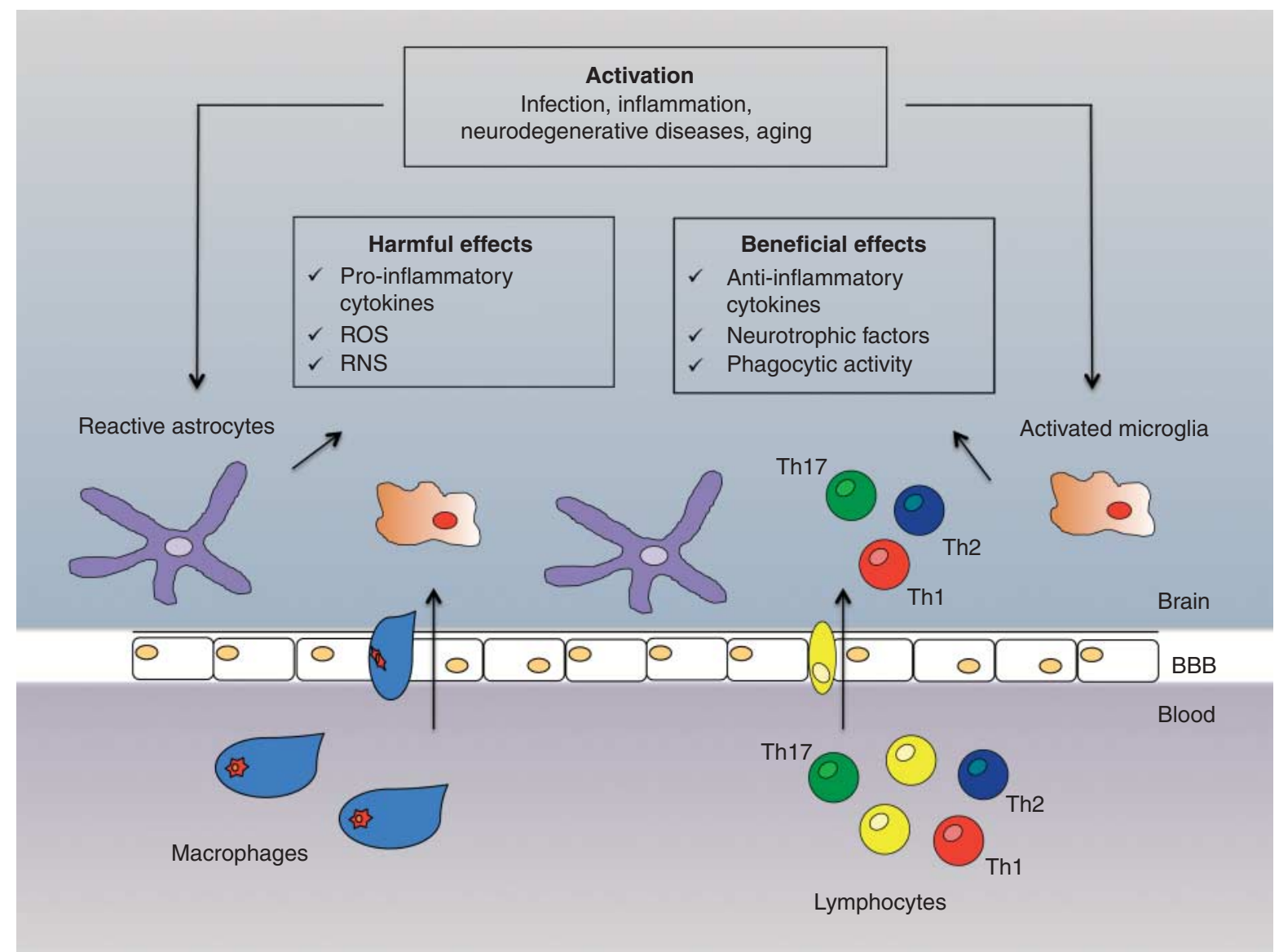

Figure 2 Inflammatory processes that occur in the CNS. Different events (inflammation, infection, aging, neurodegenerative diseases) could be the causative factor for the activation of microglia and astrocytes, the immune cells of CNS. It leads to a series of concomitant detrimental and beneficial effects. Harmful glial-mediated effects include the production of cytotoxic molecules (ROS, reactive oxygen species and RNS, reactive nitrogen species) and pro-inflammatory cytokines (IL1 $\beta$, TNF- $\alpha$, IL6). By contrast, glial cells also mediate positive and reparative effects, including the release of tropic factors and anti-inflammatory cytokines (IL10, TGF- $\beta$ ), and the clearance of cellular debris by phagocytosis. The neuroinflammation is often accompanied by the presence of peripheral immune cells (macrophages and lymphocytes) that cross the compromised BBB and sustain the inflammatory reactions in the CNS.

into Th1, Th2, and Th17 subsets depending on the cytokine milieu (Liew 2002). Th1 cells are largely considered to be pro-inflammatory in nature, aiding in the activation of macrophages and other immune cell subsets (Wee Yong 2010), while Th2 cells are considered regulatory/anti-inflammatory by virtue of the cytokines produced, which include interleukin (IL) 4, IL5, IL10, and IL13 (Wee Yong 2010). A third arm of differentiation of the Th cell is to the proinflammatory Th17 subset characterized by the production of IL17 (Kebir et al. 2007). Finally another subclass is regulatory $\mathrm{T}$ cells (Tregs), involved in the control of immune homeostasis and self-tolerance (Mills 2004).

As it appears from the mediators produced and the cell types recruited, neuroinflammation is a two-edged sword. In most cases it constitutes a beneficial process for the CNS, since it tends to minimize the injury and contributes to the repair of damaged tissue (Czlonkowska \& Kurkowska-Jastrzebska 2011). However, in some situations (Fig. 2), when the insults may persists and/or the inflammatory process may get out of control, the chronic activation of the immune response could be harmful. A shift from a homeostatic balance of inflammatory mediators toward a proinflammatory state has been observed not only in 'classical' pathological conditions but also in aging (Fig. 2; Viviani \& Boraso 2011). In particular, the balance between pro- and anti-inflammatory cytokines is lost during aging, possibly contributing to an unsuccessful maintenance at the molecular, cellular, and tissue level leading to age-related dysfunction as well as to an enhanced brain vulnerability to diseases, pathogens, environmental factors, or stress. 


\section{Neuroactive steroids as neuroinflammatory modulators}

It is well established that numerous pathologies show differences in etiology and progression according to sex. Autoimmune diseases, for example, and in particular, multiple sclerosis (MS), have a female preponderance (Hughes 2012). Also neurodegenerative diseases, like for instance Alzheimer's disease (AD) and Parkinson's disease (PD), show differences between the sexes in susceptibility and outcomes in response to therapies (Melcangi \& Garcia-Segura 2010). Indeed, women seem to be more affected than men in $\mathrm{AD}$ and protected from $\mathrm{PD}$, with a better response to levodopa treatment (Melcangi \& Garcia-Segura 2010). Moreover, sex differences on response to treatment are also reported after brain injury, with women showing better cognitive performance than men after therapy (Melcangi \& Garcia-Segura 2010).

The influence of the hormonal milieu on the etiopathogenesis of these conditions has been supported also by other observations done both in humans and animal models. Actually, changes in neuroactive steroid levels are evident in autopsy brain tissue from AD, PD, and MS patients (Naylor et al. 2010, Luchetti et al. 2011a,b, Noorbakhsh et al. 2011); similarly significant modifications happen also in the CNS of PD and experimental autoimmune encephalomyelitis (EAE) models as well as of brain or spinal trauma (Labombarda et al. 2006, Meffre et al. 2007, Caruso et al. 2010, Giatti et al. 2010, 2012, Melcangi et al. 2012). Moreover, the variation of hormonal levels in conditions such as castration, pregnancy, and the phase of estrous cycle may also influence the course of pathologies (Melcangi \& Garcia-Segura 2010).

As mentioned above, neuroinflammation is an important feature of these pathologies. Therefore, also the effect of neuroactive steroids on neuroinflammatory pathways has been specifically analyzed. Several observations have been obtained in vitro, using cultures of microglia or astrocytes exposed to lipopolysaccharide (LPS). These findings have been recently reviewed (Arevalo et al. 2012), therefore, in this study, we focus our attention on in vivo observations obtained in experimental animal models. In particular, several observations have been obtained in MS animal models and following CNS injury. For instance, in EAE animals, estrogen treatment reduces the proinflammatory cytokines, such as tumor necrosis factor (TNF)- $\alpha$, interferon (IFN)- $\gamma$, and IL6; chemokines and their receptors (e.g. CCL2, CCL3, CXCL2, CCR2, CCR3, and CXCR5), and increases anti-inflammatory transforming growth factor (TGF)- $\beta 2$ and -3 (Spence \& Voskuhl 2012). Moreover, their treatment suppresses Th1 (Bebo et al. 2001, Offner 2004) and Th17 cell (Wang et al. 2009) functions, promoting Treg cell regulation (Offner 2004). In the same animal model, other evidences report that PROG was able to reduce inflammatory markers (i.e. microglia activation, IL1 $\beta$, IL2, and IL17) (Yates et al. 2010, Giatti et al. 2012).

In experimental models of injury, such as the traumatic brain injury (TBI) model, PROG treatment reduces edema, accumulation of astrocytes in the cortex, nuclear factor kappa B (NFkB) p65, active C3 fragments, IL1 $\beta$, and TNF- $\alpha$ (Garcia-Estrada et al. 1993, Grossman et al. 2004, He et al. 2004, Pettus et al. 2005, Feeser \& Loria 2011). Moreover, it attenuates the reaction of astrocytes and microglial/macrophage cells in spinal cord injury models (Garay et al. 2011, Labombarda et al. 2011) and decreases the lesion volume and the expression of IL1 $\beta$, inducible nitric oxide synthase (iNOS; Gibson et al. 2008), ionized calcium-binding adapter molecule 1 (Iba1), and cyclooxygenase-2 in ischemic stroke models (Jiang et al. 2011). Also, testosterone treatment in TBI decreases vimentin, MHCII, and GFAP immunoreactive cells (Garcia-Estrada et al. 1993, Barreto et al. 2007) and after middle cerebral artery occlusion decreases GFAP immunostaining and astrocyte hypertrophy around the infarcted area (Pan et al. 2005). All these data underline the ability of neuroactive steroids to positively influence the inflammatory events in different neurodegenerative conditions by suppressing the pro-inflammatory and emphasizing the anti-inflammatory response.

Anti-inflammatory effects have been also reported after treatment with testosterone or PROG metabolites. Again, in the EAE model DHT reduces pro-inflammatory IFN- $\gamma$ whereas it increases anti-inflammatory IL10 (Dalal et al. 1997), and THP treatment reduces the immunoreactivity of Ibal, the monocytoid cell marker, and $\mathrm{CD} 3 \varepsilon$, a lymphocytic marker, in lumbar spinal cord (Noorbakhsh et al. 2011). In particular, THP diminishes phorbol ester myristate-induced expression of proinflammatory genes in primary monocyte-derived macrophage cultures, while it does not affect antigenspecific proliferation of $\mathrm{CD} 4+\mathrm{T}$ cells as well as the expression of IFN- $\gamma$ and IL17 in vitro in the presence of myelin oligodendrocyte glycoprotein (Noorbakhsh et al. 2011). These results, together with the absence of monocytoid and lymphocytic markers in the spinal cord, suggest that THP specifically inhibits the activation of both macrophages and microglia as well as the penetration of circulating lymphocytes and macrophages toward the CNS, thus preventing the exacerbation of the immune response. Consistent with the role of a deregulated inflammatory response in the progression of CNS diseases, THP treatment diminishes EAE severity (Noorbakhsh et al. 2011). THP anti-inflammatory effect seems to apply also to CNS diseases different in nature from EAE. Indeed, in ischemic stroke, THP is able to reduce the infarct size, 
production of pro-inflammatory cytokines like TNF- $\alpha$ and IL6, as well as to protect BBB disruption (Ishrat et al. 2010). Moreover, in the TBI model this neuroactive metabolite of PROG decreases the expression of IL1 $\beta$, TNF- $\alpha$ (He et al. 2004) and increases CD55, a potent inhibitor of the complement convertases that are activators of the inflammatory cascade (VanLandingham et al. 2007). Although no direct evidence exists, GABA-A receptors have been evoked to explain part of the anti-inflammatory effect of THP. Proofs of concept are the observations that i) THP per se does not act through the classical intra-nuclear PR but in its action recruits GABA-A receptors (Lambert et al. 2003, Belelli \& Lambert 2005), ii) this neurotransmitter receptor is also expressed on resident and circulating monocytoid cells of the immune system (Alam et al. 2006, Bhat et al. 2010) as well as on astrocyte and microglia (Lee et al. 2011), and iii) GABA suppresses the reactive response of glia to the inflammatory stimulants LPS and IFN- $\gamma$ by inhibiting induction of inflammatory pathways mediated by NFkB and P38 MAP kinase (Lee et al. 2011). Nevertheless, as THP can be reversibly converted to DHP (Melcangi et al. 2008), the recruitment of the classical nuclear PR cannot be radically excluded.

As demonstrated by Barreto et al. (2007), the effect of testosterone in reducing reactive astroglia and microglia in the TBI model seems to be ascribed to the conversion of this neuroactive steroid into its metabolites, $17 \beta-\mathrm{E}_{2}$ (i.e. by ARO activity) or DHT (i.e. by the enzyme $5 \alpha-R$ ). Indeed, treatment with these metabolites may partially mimic the effect of testosterone (Barreto et al. 2007). Similar observations were obtained in the case of PROG. Indeed, after kainic acid injection, PROG as well as its metabolites (i.e. DHP and THP) reduces reactive gliosis (Ciriza et al. 2004). Inhibition of PROG-metabolizing enzymes (i.e. $5 \alpha-\mathrm{R}$ and $3 \alpha-$-HSD) blocked the anti-gliotic effect of PROG (Ciriza et al. 2006). This is a very interesting finding in light of the observation that in experimental models reproducing different neurological diseases, the levels of neuroactive steroids and particularly the conversions of PROG and testosterone into their metabolites are affected (Labombarda et al. 2006, Meffre et al. 2007, Caruso et al. 2008, 2010, Giatti et al. 2010, Pesaresi et al. 2010b, Melcangi et al. 2012). On this basis, it is possible to hypothesize that treatment with metabolites might be more effective than treatment with the substrate molecule in regulating the neuroinflammatory response. Thus, exploring the potential antiinflammatory effects of neuroactive steroid metabolites, together with their mechanism of action, in neurodegenerative events may provide important advances to a more effective therapeutic approach. This hypothesis is strengthened by recent in vitro observations, obtained with androstenediol (i.e. a metabolite of DHEA) showing that i) LPS decreases the expression of $17 \beta$-HSD (i.e. the enzyme converting DHEA into androstenediol) in microglia cultures and ii) androstenediol, through the interaction with ER $\beta$, represses the transcription of pro-inflammatory mediators such as IL6, IL1 $\beta$, and iNOS in microglia or astrocytes (Saijo et al. 2011). In line with these in vitro observations, in vivo treatment with androstenediol has been reported to be more potent than its precursor (i.e. DHEA) in blocking the ability of LPS to induce IL6 expression in the substantia nigra (Saijo et al. 2011).

\section{Concluding remarks and perspectives}

Neuroinflammation is a process that requires to be regulated because both deficient and excessive responses will result in pathological conditions. In particular, chronic inflammation is a long-standing and often self-perpetuating response that may negatively affect neuronal function and viability, thus contributing to disease progression. Understanding CNS immunity requires attention to the temporary relation between insult, inflammatory response, and control of pro- and anti-inflammatory processes. Like in a symphony, each of these aspects is necessary and instrumental for a harmonic composition that will be reached only under tight control of every single step. Based on the dual role of inflammation, a proper anti-inflammatory approach should not simply block the onset of the process. In doing so, the deleterious effects of inflammation will be inhibited, but at the same time the inflammatory pathways that lead to neuroprotection will not be preserved. A possible approach to control neuroinflammation could consist of the restoration of the feedback mechanisms that enable the brain to regulate

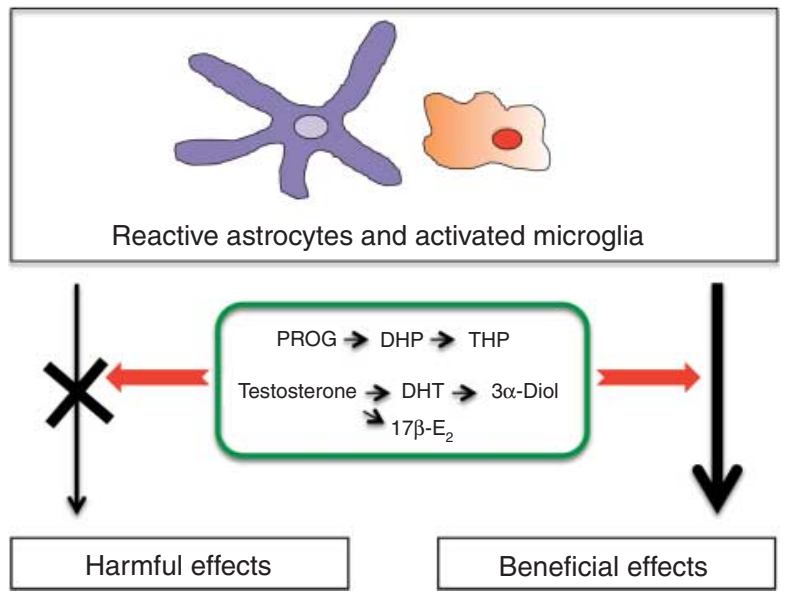

Figure 3 Progesterone and testosterone metabolites, reducing pro-inflammatory and promoting anti-inflammatory response of activated glial cells, may represent novel therapeutic approaches to reduce brain inflammation. 
the process. This goal might be reached respecting the timing and local control of inflammation in order to boost the endogenous neuroprotective response directly or interfering with the mechanisms that blunt this response in conditions of injury. In this scenario, neuroactive steroids together with their metabolites provide several points for discussion and present several attractive features to be considered as effective and promising anti-inflammatory mediators. Neuroactive steroids have been proved to positively affect neuroinflammation, also by inhibiting the pro-inflammatory and reinforcing the anti-inflammatory response (Fig. 3). Their action is regulated by a dynamic system based on a differential expression and distribution of specific metabolic enzymes and receptors, both sensitive to pathological stages. In addition, neuroactive steroid metabolism, by providing a plethora of compounds characterized by different potency and mechanisms, might modulate diverse aspects of neuroinflammation. Although the observations so far obtained suggest a beneficial effect of neuroactive steroids, timing, location, metabolism, and molecular mechanisms recruited in modulating neuroinflammation remain to be still clarified. Deciphering the setting of the neuroactive steroid system along with the development of different stages of neuroinflammation and the cross-talk between these two processes will be instrumental for the development of novel approaches aimed at restoring a 'physiological' neuroinflammation.

\section{Declaration of interest}

The authors declare that there is no conflict of interest that could be perceived as prejudicing the impartiality of the review.

\section{Funding}

The financial support of Fondazione San Paolo (Progetto Neuroscienze PF-2009.1180) to R C M is gratefully acknowledged.

\section{References}

Alam S, Laughton DL, Walding A \& Wolstenholme AJ 2006 Human peripheral blood mononuclear cells express GABAA receptor subunits. Molecular Immunology 43 1432-1442. (doi:10.1016/ j.molimm.2005.07.025)

Arevalo MA, Santos-Galindo M, Acaz-Fonseca E, Azcoitia I \& Garcia-Segura LM 2012 Gonadal hormones and the control of reactive gliosis. Hormones and Behavior. In press. (doi:10.1016/ j.yhbeh.2012.02.021)

Barreto G, Veiga S, Azcoitia I, Garcia-Segura LM \& Garcia-Ovejero D 2007 Testosterone decreases reactive astroglia and reactive microglia after brain injury in male rats: role of its metabolites, oestradiol and dihydrotestosterone. European Journal of Neuroscience 25 3039-3046. (doi:10.1111/j.1460-9568.2007.05563.x)

Baulieu EE 1998 Neurosteroids: a novel function of the brain. Psychoneuroendocrinology 23 963-987.
Bebo BF Jr, Fyfe-Johnson A, Adlard K, Beam AG, Vandenbark AA \& Offner H 2001 Low-dose estrogen therapy ameliorates experimental autoimmune encephalomyelitis in two different inbred mouse strains. Journal of Immunology 166 2080-2089.

Belelli D \& Lambert JJ 2005 Neurosteroids: endogenous regulators of the GABA(A) receptor. Nature Reviews. Neuroscience 6 565-575. (doi:10.1038/nrn1703)

Benarroch EE 2005 Neuron-astrocyte interactions: partnership for normal function and disease in the central nervous system. Mayo Clinic Proceedings 80 1326-1338. (doi:10.4065/80.10.1326)

Bhat R, Axtell R, Mitra A, Miranda M, Lock C, Tsien RW \& Steinman L 2010 Inhibitory role for GABA in autoimmune inflammation. PNAS 107 2580-2585. (doi:10.1073/pnas.0915139107)

Block ML, Zecca L \& Hong JS 2007 Microglia-mediated neurotoxicity: uncovering the molecular mechanisms. Nature Reviews. Neuroscience 8 57-69. (doi:10.1038/nrn2038)

Brinton RD \& Wang JM 2006 Therapeutic potential of neurogenesis for prevention and recovery from Alzheimer's disease: allopregnanolone as a proof of concept neurogenic agent. Current Alzheimer Research 3 185-190. (doi:10.2174/156720506777632817)

Brinton RD, Thompson RF, Foy MR, Baudry M, Wang J, Finch CE, Morgan TE, Pike CJ, Mack WJ, Stanczyk FZ et al. 2008 Progesterone receptors: form and function in brain. Frontiers in Neuroendocrinology 29 313-339. (doi:10.1016/j.yfrne.2008.02.001)

Caruso D, Scurati S, Maschi O, De Angelis L, Roglio I, Giatti S, Garcia-Segura LM \& Melcangi RC 2008 Evaluation of neuroactive steroid levels by liquid chromatography-tandem mass spectrometry in central and peripheral nervous system: effect of diabetes. Neurochemistry International 52 560-568. (doi:10.1016/j.neuint.2007. 06.004)

Caruso D, D'Intino G, Giatti S, Maschi O, Pesaresi M, Calabrese D, Garcia-Segura LM, Calza L \& Melcangi RC 2010 Sex-dimorphic changes in neuroactive steroid levels after chronic experimental autoimmune encephalomyelitis. Journal of Neurochemistry 114 921-932. (doi:10.1111/j.1471-4159.2010.06825.x)

Cho BP, Song DY, Sugama S, Shin DH, Shimizu Y, Kim SS, Kim YS \& Joh TH 2006 Pathological dynamics of activated microglia following medial forebrain bundle transection. Glia 53 92-102. (doi:10.1002/ glia.20265)

Ciriza I, Azcoitia I \& Garcia-Segura LM 2004 Reduced progesterone metabolites protect rat hippocampal neurones from kainic acid excitotoxicity in vivo. Journal of Neuroendocrinology 16 58-63. (doi:10.1111/j.1365-2826.2004.01121.x)

Ciriza I, Carrero P, Frye CA \& Garcia-Segura LM 2006 Reduced metabolites mediate neuroprotective effects of progesterone in the adult rat hippocampus. The synthetic progestin medroxyprogesterone acetate (Provera) is not neuroprotective. Journal of Neurobiology 66 916-928. (doi:10.1002/neu.20293)

Czlonkowska A \& Kurkowska-Jastrzebska I 2011 Inflammation and gliosis in neurological diseases - clinical implications. Journal of Neuroimmunology 231 78-85. (doi:10.1016/j.jneuroim.2010.09.020)

Dalal M, Kim S \& Voskuhl RR 1997 Testosterone therapy ameliorates experimental autoimmune encephalomyelitis and induces a $\mathrm{T}$ helper 2 bias in the autoantigen-specific T lymphocyte response. Journal of Immunology 159 3-6.

Djebaili M, Hoffman SW \& Stein DG 2004 Allopregnanolone and progesterone decrease cell death and cognitive deficits after a contusion of the rat pre-frontal cortex. Neuroscience 123 349-359. (doi:10.1016/j.neuroscience.2003.09.023)

DonCarlos LL, Sarkey S, Lorenz B, Azcoitia I, Garcia-Ovejero D, Huppenbauer C \& Garcia-Segura LM 2006 Novel cellular phenotypes and subcellular sites for androgen action in the forebrain. Neuroscience 138 801-807. (doi:10.1016/j.neuroscience. 2005.06.020)

Farina C, Aloisi F \& Meinl E 2007 Astrocytes are active players in cerebral innate immunity. Trends in Immunology 28 138-145. (doi:10.1016/j.it.2007.01.005) 
Feeser VR \& Loria RM 2011 Modulation of traumatic brain injury using progesterone and the role of glial cells on its neuroprotective actions. Journal of Neuroimmunology 237 4-12. (doi:10.1016/j. jneuroim.2011.06.007)

Garay L, Tungler V, Deniselle MC, Lima A, Roig P \& De Nicola AF 2011 Progesterone attenuates demyelination and microglial reaction in the lysolecithin-injured spinal cord. Neuroscience 192 588-597. (doi:10.1016/j.neuroscience.2011.06.065)

Garcia-Estrada J, Del Rio JA, Luquin S, Soriano E \& Garcia-Segura LM 1993 Gonadal hormones down-regulate reactive gliosis and astrocyte proliferation after a penetrating brain injury. Brain Research 628 271-278. (doi:10.1016/0006-8993(93)90964-O)

García-Ovejero D, Veiga S, García-Segura LM \& Doncarlos LL 2002 Glial expression of estrogen and androgen receptors after rat brain injury. Journal of Comparative Neurology 450 256-271. (doi:10.1002/ cne.10325)

Garcia-Segura LM \& Balthazart J 2009 Steroids and neuroprotection: new advances. Frontiers in Neuroendocrinology 30 v-ix. (doi:10.1016/ j.yfrne.2009.04.006)

Garcia-Segura LM \& Melcangi RC 2006 Steroids and glial cell function. Glia 54 485-498. (doi:10.1002/glia.20404)

Garcia-Segura LM, Veiga S, Sierra A, Melcangi RC \& Azcoitia I 2003 Aromatase: a neuroprotective enzyme. Progress in Neurobiology 71 31-41. (doi:10.1016/j.pneurobio.2003.09.005)

Ghoumari AM, Ibanez C, El-Etr M, Leclerc P, Eychenne B, O'Malley BW, Baulieu EE \& Schumacher M 2003 Progesterone and its metabolites increase myelin basic protein expression in organotypic slice cultures of rat cerebellum. Journal of Neurochemistry $\mathbf{8 6} 848-859$. (doi:10.1046/j.1471-4159.2003.01881.x)

Giachino C, Galbiati M, Fasolo A, Peretto P \& Melcangi RC 2003 Neurogenesis in the subependymal layer of the adult rat: a role for neuroactive derivatives of progesterone. Annals of the New York Academy of Sciences 1007 335-339. (doi:10.1196/annals.1286.032)

Giachino C, Galbiati M, Fasolo A, Peretto P \& Melcangi RC 2004 Effects of progesterone derivatives, dihydroprogesterone and tetrahydroprogesterone, on the subependymal layer of the adult rat. Journal of Neurobiology 58 493-502. (doi:10.1002/neu.10290)

Giatti S, D'Intino G, Maschi O, Pesaresi M, Garcia-Segura LM, Calza L, Caruso D \& Melcangi RC 2010 Acute experimental autoimmune encephalomyelitis induces sex dimorphic changes in neuroactive steroid levels. Neurochemistry International 56 118-127. (doi:10.1016/ j.neuint.2009.09.009)

Giatti S, Caruso D, Boraso M, Abbiati F, Ballarini E, Calabrese D, Pesaresi M, Rigolio R, Santos-Galindo M, Viviani B et al. 2012 Neuroprotective effects of progesterone in chronic experimental autoimmune encephalomyelitis. Journal of Neuroendocrinology $\mathbf{2 4}$ 851-861. (doi:10.1111/j.1365-2826.2012.02284.x)

Gibson CL, Gray LJ, Bath PM \& Murphy SP 2008 Progesterone for the treatment of experimental brain injury; a systematic review. Brain 131 318-328. (doi:10.1093/brain/awm183)

Glass CK, Saijo K, Winner B, Marchetto MC \& Gage FH 2010 Mechanisms underlying inflammation in neurodegeneration. Cell 140 918-934. (doi:10.1016/j.cell.2010.02.016)

Gottfried-Blackmore A, Sierra A, Jellinck PH, McEwen BS \& Bulloch K 2008 Brain microglia express steroid-converting enzymes in the mouse. Journal of Steroid Biochemistry and Molecular Biology 109 96-107. (doi:10.1016/j.jsbmb.2007.12.013)

Grossman KJ, Goss CW \& Stein DG 2004 Effects of progesterone on the inflammatory response to brain injury in the rat. Brain Research 1008 29-39. (doi:10.1016/j.brainres.2004.02.022)

Hanisch UK \& Kettenmann H 2007 Microglia: active sensor and versatile effector cells in the normal and pathologic brain. Nature Neuroscience 10 1387-1394. (doi:10.1038/nn1997)

He J, Evans CO, Hoffman SW, Oyesiku NM \& Stein DG 2004 Progesterone and allopregnanolone reduce inflammatory cytokines after traumatic brain injury. Experimental Neurology 189 404-412. (doi:10.1016/j.expneurol.2004.06.008)
Hughes GC 2012 Progesterone and autoimmune disease. Autoimmunity Reviews 11 A502-A514. (doi:10.1016/j.autrev.2011.12.003)

Ishrat T, Sayeed I, Atif F, Hua F \& Stein DGCP 2010 Progesterone and allopregnanolone attenuate blood-brain barrier dysfunction following permanent focal ischemia by regulating the expression of matrix metalloproteinases. Experimental Neurology 226 183-190. (doi:10.1016/j.expneurol.2010.08.023)

Jellinck PH, Kaufmann M, Gottfried-Blackmore A, Croft G, Byford V, McEwen BS, Jones G \& Bulloch K 2006 Dehydroepiandrosterone (DHEA) metabolism in the brain: identification by liquid chromatography/mass spectrometry of the delta-4-isomer of DHEA and related steroids formed from androstenedione by mouse BV2 microglia. Journal of Steroid Biochemistry and Molecular Biology 98 41-47. (doi:10.1016/j.jsbmb.2005.07.006)

Jellinck PH, Kaufmann M, Gottfried-Blackmore A, McEwen BS, Jones G \& Bulloch K 2007 Selective conversion by microglia of dehydroepiandrosterone to 5-androstenediol-A steroid with inherent estrogenic properties. Journal of Steroid Biochemistry and Molecular Biology 107 156-162. (doi:10.1016/j. jsbmb.2007.04.004)

Jiang C, Cui K, Wang J \& He Y 2011 Microglia and cyclooxygenase-2: possible therapeutic targets of progesterone for stroke. International Immunopharmacology 11 1925-1931. (doi:10.1016/j.intimp. 2011.08.001)

Kebir H, Kreymborg K, Ifergan I, Dodelet-Devillers A, Cayrol R, Bernard M, Giuliani F, Arbour N, Becher B \& Prat A 2007 Human TH17 lymphocytes promote blood-brain barrier disruption and central nervous system inflammation. Nature Medicine 13 1173-1175. (doi:10.1038/nm1651)

Kipp M, Amor S, Krauth R \& Beyer C 2012 Multiple sclerosis: neuroprotective alliance of estrogen-progesterone and gender. Frontiers in Neuroendocrinology 33 1-16. (doi:10.1016/j.yfrne. 2012.01.001)

Labombarda F, Pianos A, Liere P, Eychenne B, Gonzalez S, Cambourg A, De Nicola AF, Schumacher M \& Guennoun R 2006 Injury elicited increase in spinal cord neurosteroid content analyzed by gas chromatography mass spectrometry. Endocrinology 147 1847-1859. (doi:10.1210/en.2005-0955)

Labombarda F, Gonzalez S, Lima A, Roig P, Guennoun R, Schumacher M \& De Nicola AF 2011 Progesterone attenuates astro- and microgliosis and enhances oligodendrocyte differentiation following spinal cord injury. Experimental Neurology 231 135-146. (doi:10.1016/j.expneurol.2011.06.001)

Lambert JJ, Belelli D, Peden DR, Vardy AW \& Peters JA 2003 Neurosteroid modulation of GABAA receptors. Progress in Neurobiology 71 67-80. (doi:10.1016/j.pneurobio.2003.09.001)

Lavaque E, Mayen A, Azcoitia I, Tena-Sempere M \& Garcia-Segura LM $2006 a$ Sex differences, developmental changes, response to injury and cAMP regulation of the mRNA levels of steroidogenic acute regulatory protein, cytochrome $\mathrm{p} 450 \mathrm{scc}$, and aromatase in the olivocerebellar system. Journal of Neurobiology 66 308-318. (doi:10.1002/neu.20221)

Lavaque E, Sierra A, Azcoitia I \& Garcia-Segura LM $2006 b$ Steroidogenic acute regulatory protein in the brain. Neuroscience 138 741-747. (doi:10.1016/j.neuroscience.2005.05.060)

Lee M, Schwab C \& McGeer PL 2011 Astrocytes are GABAergic cells that modulate microglial activity. Glia 59 152-165. (doi:10.1002/ glia.21087)

Liao H, Bu WY, Wang TH, Ahmed S \& Xiao ZC 2005 Tenascin-R plays a role in neuroprotection via its distinct domains that coordinate to modulate the microglia function. Journal of Biological Chemistry $\mathbf{2 8 0}$ 8316-8323. (doi:10.1074/jbc.M412730200)

Liew FY $2002 \mathrm{~T}(\mathrm{H}) 1$ and T(H) 2 cells: a historical perspective. Nature Reviews. Immunology 2 55-60. (doi:10.1038/nri705)

Liu B, Gao HM, Wang JY, Jeohn GH, Cooper CL \& Hong JS 2002 Role of nitric oxide in inflammation-mediated neurodegeneration. Annals of the New York Academy of Sciences 962 318-331. (doi:10.1111/ j.1749-6632.2002.tb04077.x) 
Luchetti S, Bossers K, Van de Bilt S, Agrapart V, Morales RR, Frajese GV \& Swaab DF 2011 $a$ Neurosteroid biosynthetic pathways changes in prefrontal cortex in Alzheimer's disease. Neurobiology of Aging 32 1964-1976. (doi:10.1016/j.neurobiolaging.2009.12.014)

Luchetti S, Huitinga I \& Swaab DF $2011 b$ Neurosteroid and GABA-A receptor alterations in Alzheimer's disease, Parkinson's disease and multiple sclerosis. Neuroscience 191 6-21. (doi:10.1016/j.neuroscience.2011.04.010)

Meffre D, Pianos A, Liere P, Eychenne B, Cambourg A, Schumacher M, Stein DG \& Guennoun R 2007 Steroid profiling in brain and plasma of male and pseudopregnant female rats after traumatic brain injury: analysis by gas chromatography/mass spectrometry. Endocrinology 148 2505-2517. (doi:10.1210/en.2006-1678)

Melcangi RC \& Garcia-Segura LM 2010 Sex-specific therapeutic strategies based on neuroactive steroids: in search for innovative tools for neuroprotection. Hormones and Behavior 57 2-11. (doi:10.1016/j.yhbeh.2009.06.001)

Melcangi RC, Magnaghi V, Galbiati M \& Martini L 2001 Glial cells: a target for steroid hormones. Progress in Brain Research 132 31-40. (doi:10.1016/S0079-6123(01)32063-0)

Melcangi RC, Garcia-Segura LM \& Mensah-Nyagan AG 2008 Neuroactive steroids: state of the art and new perspectives. Cellular and Molecular Life Sciences 65 777-797. (doi:10.1007/s00018-0077403-5)

Melcangi RC, Panzica G \& Garcia-Segura LM 2011 Neuroactive steroids: focus on human brain. Neuroscience 191 1-5. (doi:10.1016/ j.neuroscience.2011.06.024)

Melcangi RC, Caruso D, Levandis G, Abbiati F, Armentero MT \& Blandini F 2012 Modifications of neuroactive steroid levels in an experimental model of nigrostriatal degeneration: potential relevance to the pathophysiology of Parkinson's disease. Journal of Molecular Neuroscience 46 177-183. (doi:10.1007/s12031$011-9570-\mathrm{y})$

Meyer U, Schwarz MJ \& Muller N 2011 Inflammatory processes in schizophrenia: a promising neuroimmunological target for the treatment of negative/cognitive symptoms and beyond. Pharmacology and Therapeutics 132 96-110. (doi:10.1016/j. pharmthera.2011.06.003)

Mills KH 2004 Regulatory T cells: friend or foe in immunity to infection? Nature Reviews. Immunology 4 841-855. (doi:10.1038/ nri1485)

Morgan SC, Taylor DL \& Pocock JM 2004 Microglia release activators of neuronal proliferation mediated by activation of mitogenactivated protein kinase, phosphatidylinositol-3-kinase/Akt and delta-Notch signalling cascades. Journal of Neurochemistry 90 89-101. (doi:10.1111/j.1471-4159.2004.02461.x)

Moss DW \& Bates TE 2001 Activation of murine microglial cell lines by lipopolysaccharide and interferon-gamma causes NO-mediated decreases in mitochondrial and cellular function. European Journal of Neuroscience 13 529-538. (doi:10.1046/j.1460-9568.2001. 01418.x)

Muller FJ, Snyder EY \& Loring JF 2006 Gene therapy: can neural stem cells deliver? Nature Reviews. Neuroscience 7 75-84. (doi:10.1038/ nrn1829)

Naylor JC, Kilts JD, Hulette CM, Steffens DC, Blazer DG, Ervin JF, Strauss JL, Allen TB, Massing MW, Payne VM et al. 2010 Allopregnanolone levels are reduced in temporal cortex in patients with Alzheimer's disease compared to cognitively intact control subjects. Biochimica et Biophysica Acta 1801 951-959. (doi:10.1016/ j.bbalip.2010.05.006)

Noorbakhsh F, Ellestad KK, Maingat F, Warren KG, Han MH, Steinman L, Baker GB \& Power C 2011 Impaired neurosteroid synthesis in multiple sclerosis. Brain 134 2703-2721. (doi:10.1093/brain/awr200)

Oehmichen W \& Gencic M 1975 Experimental studies on kinetics and functions of monuclear phagozytes of the central nervous system. Acta Neuropathologica (Suppl 6) 285-290.
Offner H 2004 Neuroimmunoprotective effects of estrogen and derivatives in experimental autoimmune encephalomyelitis: therapeutic implications for multiple sclerosis. Journal of Neuroscience Research 78 603-624. (doi:10.1002/jnr.20330)

Pan Y, Zhang H, Acharya AB, Patrick PH, Oliver D \& Morley JE 2005 Effect of testosterone on functional recovery in a castrate male rat stroke model. Brain Research 1043 195-204. (doi:10.1016/j.brainres. 2005.02.078)

Panzica GC \& Melcangi RC 2008 The endocrine nervous system: source and target for neuroactive steroids. Brain Research Reviews 57 271-276. (doi:10.1016/j.brainresrev.2008.02.002)

Panzica GC, Balthazart J, Frye CA, Garcia-Segura LM, Herbison AE, Mensah-Nyagan AG, McCarthy MM \& Melcangi RC 2012 Milestones on steroids and the nervous system: 10 years of basic and translational research. Journal of Neuroendocrinology 24 1-15. (doi:10.1111/j.1365-2826.2011.02265.x)

Papadopoulos V, Baraldi M, Guilarte TR, Knudsen TB, Lacapere JJ, Lindemann P, Norenberg MD, Nutt D, Weizman A, Zhang MR et al. 2006 Translocator protein (18kDa): new nomenclature for the peripheral-type benzodiazepine receptor based on its structure and molecular function. Trends in Pharmacological Sciences 27 402-409. (doi:10.1016/j.tips.2006.06.005)

Pelletier G 2010 Steroidogenic enzymes in the brain: morphological aspects. Progress in Brain Research 181 193-207. (doi:10.1016/S00796123(08)81011-4)

Pesaresi M, Giatti S, Calabrese D, Maschi O, Caruso D \& Melcangi RC $2010 a$ Dihydroprogesterone increases the gene expression of myelin basic protein in spinal cord of diabetic rats. Journal of Molecular Neuroscience 42 135-139. (doi:10.1007/ s12031-010-9344-y)

Pesaresi M, Maschi O, Giatti S, Garcia-Segura LM, Caruso D \& Melcangi RC $2010 b$ Sex differences in neuroactive steroid levels in the nervous system of diabetic and non-diabetic rats. Hormones and Behavior 57 46-55. (doi:10.1016/j.yhbeh.2009.04.008)

Pettus EH, Wright DW, Stein DG \& Hoffman SW 2005 Progesterone treatment inhibits the inflammatory agents that accompany traumatic brain injury. Brain Research 1049 112-119. (doi:10.1016/j.brainres.2005.05.004)

Ridet JL, Malhotra SK, Privat A \& Gage FH 1997 Reactive astrocytes: cellular and molecular cues to biological function. Trends in Neuroscience 20 570-577. (doi:10.1016/S0166-2236 (97)01139-9)

Rock RB, Gekker G, Hu S, Sheng WS, Cheeran M, Lokensgard JR \& Peterson PK 2004 Role of microglia in central nervous system infections. Clinical Microbiology Reviews 17 942-964. (doi:10.1128/ CMR.17.4.942-964.2004)

Saijo K, Collier JG, Li AC, Katzenellenbogen JA \& Glass CK 2011 An ADIOL-ER $\beta$-CtBP transrepression pathway negatively regulates microglia-mediated inflammation. Cell 145 584-595. (doi:10.1016/ j.cell.2011.03.050)

Sawada M, Kondo N, Suzumura A \& Marunouchi T 1989 Production of tumor necrosis factor- $\alpha$ by microglia and astrocytes in culture. Brain Research 491 394-397. (doi:10.1016/0006-8993(89) 90078-4)

Schumacher M, Hussain R, Gago N, Oudinet JP, Mattern C \& Ghoumari AM 2012 Progesterone synthesis in the nervous system: implications for myelination and myelin repair. Frontiers in Neuroscience 6 10. (doi:10.3389/fnins.2012.00010)

Schwartz M, Butovsky O, Bruck W \& Hanisch UK 2006 Microglial phenotype: is the commitment reversible? Trends in Neuroscience 29 68-74. (doi:10.1016/j.tins.2005.12.005)

Sierra A, Gottfried-Blackmore AC, McEwen BS \& Bulloch K 2007 Microglia derived from aging mice exhibit an altered inflammatory profile. Glia 55 412-424. (doi:10.1002/glia.20468)

Sierra A, Gottfried-Blackmore A, Milner TA, McEwen BS \& Bulloch K 2008 Steroid hormone receptor expression and function in microglia. Glia 56 659-674. (doi:10.1002/glia.20644) 
Spence RD \& Voskuhl RR 2012 Neuroprotective effects of estrogens and androgens in CNS inflammation and neurodegeneration. Frontiers in Neuroendocrinology 33 105-115. (doi:10.1016/j.yfrne. 2011.12.001)

Sun C, Ou X, Farley JM, Stockmeier C, Bigler S, Brinton RD \& Wang JM 2012 Allopregnanolone increases the number of dopaminergic neurons in substantia nigra of a triple transgenic mouse model of Alzheimer's disease. Current Alzheimer Research 9 473-480.

Tabori NE, Stewart LS, Znamensky V, Romeo RD, Alves SE, McEwen BS \& Milner TA 2005 Ultrastructural evidence that androgen receptors are located at extranuclear sites in the rat hippocampal formation. Neuroscience 130 151-163. (doi:10.1016/j.neuroscience. 2004.08.048)

Tansey MG 2010 Inflammation in neuropsychiatric disease. Neurobiology of Disease 37 491-492. (doi:10.1016/j.nbd.2009.12.004)

Tansey MG \& Goldberg MS 2010 Neuroinflammation in Parkinson's disease: its role in neuronal death and implications for therapeutic intervention. Neurobiology of Disease 37 510-518. (doi:10.1016/j.nbd. 2009.11.004)

Tansey MG, McCoy MK \& Frank-Cannon TC 2007 Neuroinflammatory mechanisms in Parkinson's disease: potential environmental triggers, pathways, and targets for early therapeutic intervention. Experimental Neurology 208 1-25. (doi:10.1016/j.expneurol.2007.07. 004)

VanLandingham JW, Cekic M, Cutler S, Hoffman SW \& Stein DGCP 2007 Neurosteroids reduce inflammation after TBI through CD55 induction. Neuroscience Letters 425 94-98. (doi:10.1016/j.neulet. 2007.08.045)
Viviani B \& Boraso MS 2011 Cytokines and neuronal channels: a molecular basis for age-related decline of neuronal function? Experimental Gerontology 46 199-206. (doi:10.1016/j.exger.2010.09.008)

Viviani B, Corsini E, Binaglia M, Galli CL \& Marinovich M 2001 Reactive oxygen species generated by glia are responsible for neuron death induced by human immunodeficiency virus-glycoprotein 120 in vitro. Neuroscience 107 51-58. (doi:10.1016/ S0306-4522(01) 00332-3)

Wang C, Dehghani B, Li Y, Kaler LJ, Vandenbark AA \& Offner H 2009 Oestrogen modulates experimental autoimmune encephalomyelitis and interleukin-17 production via programmed death 1 . Immunology 126 329-335. (doi:10.1111/j.1365-2567.2008.03051.x)

Wee Yong V 2010 Inflammation in neurological disorders: a help or a hindrance? Neuroscientist 16 408-420. (doi:10.1177/ 1073858410371379)

Wuwongse S, Chang RC \& Law AC 2010 The putative neurodegenerative links between depression and Alzheimer's disease. Progress in Neurobiology 91 362-375. (doi:10.1016/j.pneurobio.2010.04.005)

Yates MA, Li Y, Chlebeck P, Proctor T, Vandenbark AA \& Offner H 2010 Progesterone treatment reduces disease severity and increases IL-10 in experimental autoimmune encephalomyelitis. Journal of Neuroimmunology 220 136-139. (doi:10.1016/j.jneuroim. 2010.01.013)

Received in final form 5 September 2012

Accepted 10 September 2012

Made available online as an Accepted Preprint 10 September 2012 